\title{
USE SILICA NANOPARTICLES IN CONTROLLING LATE WILT DISEASE IN MAIZE CAUSED BY HARPOPHORA MAYDIS
}

El-Shabrawy, E.M.

Plant Pathology Research Institute A.R.C. Giza, Egypt

Email - said_wsha@hotmail.com

Key Words: late wilt disease, Silica nanoparticles, Green synthesis.

\section{ABSTRACT}

Green synthesized silica nanoparticles (SiNPs) and their optimization under different $\mathrm{pH}$ values i.e., $(5,7,9,11)$ giving sizes $20,40.2,70.2$ and $95.5 \mathrm{~nm}$, were evaluated for controlling Harpophora maydis the causal agent of late wilt disease in Zea maize in vitro and in vivo. Under laboratory conditions, PDA medium revealed that all tested SiNPs sizes, 20, 40.2, 70.2 and $95.5 \mathrm{~nm}$ at different concentrations $(0.5,2.5,5$ and $10 \mathrm{ppm})$ significantly inhibited the mycelia radial growth of Harpophora maydis. Reduction increased by increasing concentration compared to control. The most efficient treatment was SiNP- $20 \mathrm{~nm}$ followed by SiNP-40.2 nm. Greenhouse experiment indicated that seed coated by SiNPs significantly reduced the infection percentage of late wilt and enhanced the germination percentage compared with check treatment $(70.8 \%)$. The SiNP-20 nm followed by SiNP-40.2 nm introduced superior reduction in disease incidence (88.2 and $87.7 \%$ reduction, respectively) at concentration $10 \mathrm{ppm}$. The lowest effect was SiNP-95.5 nm which gave 52.9\% reduction. Results of field trails during 2019-2020 growing season at Giza and Gemmeza disease nurseries indicated that treated seeds with SiNPs showed significant reduction in maize infected with late wilt compared with check plants (78.3\% and $81.7 \%$ at Giza 2019, Gemmeza 2020, respectively). Also, there were significant differences between treatments in yield average of the two seasons. The disease reduction and yield increased with increasing concentrations. The SiNPs-20 nm and SiNPs-40.2 nm treatments were the most efficient treatments in decreasing disease incidence and enhancing yield when recorded $6.7 \%$ at $10 \mathrm{ppm}$ at first season (Giza-2019) for both treatments while gave $6.7 \%$ and $8.3 \%$ in the second season at Gemmeza2020 , respectively. On the other hand, average yield were $29 \mathrm{ard} / \mathrm{fd}$ in cases of SiNP-20 nm and $27.3 \mathrm{ard} / \mathrm{fd}$ in case of SiNP-40.2 nm. In contrary, the lowest treatments were the concentration $0.5 \mathrm{ppm}$ of treatments SiNPs 95.5, $70.2 \mathrm{~nm}$. Where, the infection was $34 \%$ and average yield of $17.6 \mathrm{ard} / \mathrm{fd}$ for SiNP-95.5 nm and it was $26.3 \%$ infection \% which yielded 18 ( $\mathrm{ard} / \mathrm{fd})$ in treatment SiNP-70.2 $\mathrm{nm}$ at Gemmeza location. It could be concluded that using the green synthesized SiNPs ecologically welcomed at sizes 20 and 
$40.2 \mathrm{~nm}$, were more efficient than that with higher sizes in controlling maize late wilt disease and enhancing maize yield productivity.

\section{INTRODUCTION}

Maize (Zea mays L.) is considered as one of the most important cereal crops in Egypt. The late wilt disease of maize caused by Harpophora maydis (Games, 2000) synonymous: Cephalosporium maydis (Samra, et al., 1963) is one of the most important diseases on maize in Egypt (Sabet et al., 1966b; Ali, 2000 and Saleh \& Leslie, 2004). Moreover, Egyptian isolates of $C$. maydis vary in their morphological characters and capability to cause infection as well as their genetic structures (Saleh et al., 2003). Furthermore, the yield losses may reach up to $40 \%$ in naturally infested fields with infection up to $80 \%$ (El-Shafey and Clafline, 1999). Late wilt appears during tasseling as a rapid wilting of the lower leaves and develops to hollow and shrunken stalks with a dark yellow-to-brown or black-stained pith (El-Shafey and Claflin 1999). The pathogen is mainly a soil-borne fungus whichable to invade root tissue and colonizes the xylem (Sabet $\boldsymbol{e t}$ al. 1970). Breeding of resistant varieties of maize is the most effective method for controlling this disease (El-Shafey $\boldsymbol{e t}$ al. 1988). In recent years, using pesticide for controlling plant disease resulted in many environmental hazards. Many attempts were made to control the pathogen using chemical and biological methods (El-Mehalowy et al. 2004; Ashour et al. 2013; ElMoghazy et al., 2017 and Elshahawy and El-Sayed, 2018). Some tested fungicides worked well in pots but failed in field experiments. Therefore, many researchers are trying to find an alternative method for pesticides as inorganic nanoparticles. Nanotechnology is characterized by the formation of particles with variable sizes, shapes, chemical compositions, depending on their applications. Although chemical and physical methods may produce pure and well-defined nanoparticles, these methods are just costly and critical to the habitat (Reddy et al., 2012).

Green synthesis of nanoparticles with the help of plants as reducing agents is considered an efficient, cost effective, fast and eco-friendly in manner (Yugandhar and Savithramma, 2015a). In recent past, most of the scientists adopted green synthesis methods for the production of narrowranged particles, like calcium (Yugandhar and Savithramma, 2013), copper (Shende et al. 2015), gold (Gopinath et al. 2014), iron (Naseem and Farrukh, 2015), silica (Athinaranan et al. 2015), silver (Yugandhar and Savithramma, 2016), and zinc (Bala et al. 2015) from different medicinal plants including Nerium oleander among them, silica nanoparticles (SiNPs) were recognized as important in the fields of chemistry, physics and plant disease control due to their distinctive properties. 
Present study aims to investigate the antifungal activity of green synthesized silica nanoparticles with different sizes against Harpophora maydis, the causal agent of maize late wilt disease under in vitro and invivo conditions.

\section{MATERIAL AND METHODS \\ Synthesis of silica nanoparticles}

Synthesis of silica nanoparticles (SiNPs) was achieved with slight modifications of Adam et al. (2011) protocol. The well-ground $(20 \mathrm{~g})$ of Nerium oleander plant leaf powder was subjected to acid treatment by mixing it with $500 \mathrm{ml}$ of $1 \mathrm{M} \mathrm{HNO}_{3}$ in a $1000-\mathrm{ml}$ Erlenmeyer conical flask and stirred for $24 \mathrm{~h}$. this step was done before SiNPs synthesis to purify the reaction mixture from plant impurities (Yugandhar et al. 2015a).Mixture was centrifuged at $14.000 \mathrm{rpm}$ for 20 minutes, yielded raw silicon dioxide $\left(\mathrm{SiO}_{2}\right)$ in the form of a pellet at the bottom of centrifuge tubes. Filtrate part was discarded and $\mathrm{SiO}_{2}$ pellet was collected and washed several times with distilled water the $\mathrm{pH}$ up to (4.0-5.0). The solution was dried in an oven between 100 and $110{ }^{\circ} \mathrm{C}$ for $12 \mathrm{~h}$. The evaporated turbid solution was stirred with $500 \mathrm{ml}$ of $1 \mathrm{M}(\mathrm{NaOH})$ solution up to $24 \mathrm{~h}$ with a magnetic stirrer to reach the $\mathrm{pH}$ up to 12 to form sodium silicate. The obtained reaction mixture was separated with a suction pump and titrated with $3 \mathrm{M}\left(\mathrm{HNO}_{3}\right)$ until the $\mathrm{pH}$ was attained up to 8.5-9.0 to get the pure form of $\mathrm{SiO}_{2}$, sodium nitrate and water molecules (Yugandhar and Savithramma, 2015 b; Yugandhar et al., 2015). When $3 \mathrm{M}\left(\mathrm{HNO}_{3}\right)$ solutions was added drop wise to the purified plant mixture, color pattern of the mixture was gradually changed from brown to whitish precipitate. The contents were centrifuged at 5000 RPM for $10 \mathrm{~min}$ to separate biological admixtures. The contents were washed 3 to 4 times with distilled water and dried in a hot air oven for $12 \mathrm{~h}$ at $80^{\circ} \mathrm{C}$. The preliminary indication of (SiNPs) formation can be confirmed by its color change from brown to whitish precipitate. The obtained powder was well-ground with a mortar and pestle, and was utilized for characterization and antimicrobial studies.

\section{Characterization and optimization of SiNPs}

Ultraviolet-visible (UV-Vis) spectroscopic characterization of the obtained nanoparticles before dryingwas analyzed by using UV-Vis Spectrophotometer (Shimadzu UV-1800) at wavelengths ranged in the 200-800 nm compared with negative control (plant filtrate). Dynamic light scattering (DLS) was carried out by using a Malvern Zetasizer Nano ZS 90 (Worcestershire, UK) to determine SiNPs sizes. Microstructures were recorded on a MSAL-XD2 X-ray di-ractometer (XRD, Bruker, Karlsruhe, Germany) employing $\mathrm{Cu}$ target in the $2 \mathrm{q}$ range from $0^{\circ}$ to 80 
${ }^{\circ}(40 \mathrm{kV}, 30 \mathrm{~mA}, \lambda=1.540513 \mathrm{~A})$. Transmission electron microscopic (TEM) analysis of nanoparticles was performed by using JEOL JEM2010 (USA) with high-resolution transmission electron microscope operated between 80 and $200 \mathrm{kV}$ accelerating voltages.

\section{Optimization of silica nanoparticles sizes}

Inan attempt to produce better size controlled silica nanoparticles, the effect of the $\mathrm{pH}$ reaction was studied by varying it at a time, keeping the other experimental conditions the same. In all, the reactions, the concentrations of silica nanoparticles and the plant extract were set at 1 $\mathrm{mM}$ and $10 \mathrm{~g}$ (wet weight) of plant extract/100 $\mathrm{ml}$. The mixtures were incubated at different $\mathrm{pH}$ values $(5,7,9$ and 11) for various time periods for one month with respect to SiNPs stability. Simply by varying the $\mathrm{pH}$ value of the reaction system, size of the nanoparticles could be turned. When the reaction is completed, products were collected and thoroughly washed for several times with ethanol to obtain pure SiNPs without any by-products and finally subjected to dry vacuum at $80{ }^{\circ} \mathrm{C}$ for $3 \mathrm{~h}$. optimum reaction parameters were then selected by measuring the absorbance of resulting solutions spectrophotometric ally using a UVvisible spectrophotometer (Shimadzu UV-1800) at wavelengths ranged in the 200-800 nm. For each condition, respective controls were maintained. The hydrodynamic diameter of the formed SiNPs were measured by dynamic light scattering (DLS) using a Malvern Zetasizer Nano ZS 90 (Worcestershire, UK).

In vitro effect of nanoparticles on Harpophora maydis radial growth

A laboratory experiment was carried out to screening the inhibitory effect of SiNPs against a highly virulent Harpophora maydis (No.9) liner growth. In vitro assay was performed on Potato dextrose agar (Bilgrami \&Verma, 1981). The tested SiNPs sizes 20, 40.2, 70.2 and $95.5 \mathrm{~nm}$ at different concentrations $(0.5,2.5,5$ and $10 \mathrm{ppm})$ were poured into growth media prior to pouring in a Petri dish $(9 \mathrm{~cm}$ in diameter). Three replicates were used for each concentration. Five $\mathrm{mm}$ indiameter agar plugs were obtained from the actively growing Harpophora maydis (7 old day cultures) inoculated in the center of plates supplemented with different treatments. The plates were incubated at $28^{\circ} \mathrm{C}$ for 9 days. Colony diameters were measured every $72 \mathrm{~h}$ until full growth in control. Control plates inoculated by Harpophora maydis in growth medium without SiNPs. The percentage of inhibition zones were measured compared with control using the following formula: Inhibition rate $(\%)=(\mathrm{R}-\mathrm{r}) / \mathrm{R} \times 100$ Where $\mathrm{R}$ is radial growth of fungi in control and $\mathrm{r}$ is the radial growth of fungi in treated plates. 


\section{In vivo effect of nanoparticles on Harpophora maydis -Seed coating technique}

Seed coating was done following the method described by Bardin et al. (2004). Seeds were soaked for $15 \mathrm{~min}$. in $1 \%$ methyl cellulose (MC) solution at the rate of $3 \mathrm{ml}$ per 100 seeds. Thereafter, seeds were removed and placed in plastic bags containing silica nanoparticles with four different sizes $(20,40.2,70.2$, and $95.5 \mathrm{~nm})$ at the rate of $5 \mathrm{ml}$ per 100 seeds from different four concentrations $0.5,2.5,5$, and $10 \mathrm{ppm}$ of each SiNPs. Bags were inflated with air and shaken vigorously. Thereafter, seeds were directly planted in the infested-potted soil. Seed coated with sterile distilled water only acted as the control.

\section{-Inoculum preparation}

Substrate for fungal growth was prepared in $500 \mathrm{ml}$ glass bottles each contained $100 \mathrm{~g}$ of sorghum grains, $50 \mathrm{~g}$ of washed and $90 \mathrm{ml}$ of tap water. Bottles were autoclaved at $121^{\circ} \mathrm{C}$ for 30 min then cooled down. The fungus propagules of aggressive Harpophora maydis isolate No. 9 obtained from culture type collection of Maize and Sugar Crops Dis. Dept., Plant Pathol. Res. Inst., ARC, taken from 7 day-old culture grown on PDAY medium, were aseptically transferred into each bottle and allowed to colonize on sorghum medium for $2-3$ weeks at $27 \pm 2^{\circ} \mathrm{C}$ until sufficient growth of the fungus was obtained (El-Shafey $\boldsymbol{e t}$ al., 1979). The incubated bottles were shack every three days to ensure uniform of fungal growth. The content of the bottles of was poured out and mixed to get homogenized, and then inoculum was used for soil infestation.

\section{-Soil infestation}

Soil infestation was carried out according to (Samra et al., 1966) as follows: Batches of autoclaved clay loam soil were infested with inoculum of Harpophora maydis with soil at the rate of $30 \mathrm{~g} / \mathrm{kg}$ soiland mixed thoroughly. Infested soil was dispensed into pottery pots $(25-\mathrm{cm}-$ diameter) sterilized by $0.4 \%$ formaldehyde. Maize grains (cv. Boushy) were surface sterilized in 5\% sodium hypochlorite solution for $3 \mathrm{~min}$. then washed in sterilized distilled water for $5 \mathrm{~min}$. and air dried before sowing. Ten grains were sowed in each pot. Four pots were used for each treatment as replicates. On the other hand, autoclaved sterilized sorghum grains, mixed thoroughly with soil at the rate of $30 \mathrm{~g} / \mathrm{kg}$ soil and kept as control (check) treatment. Pots were regularly watered every other day for a week before sowing.

\section{Field experiment}

Silica nanoparticles with their four varied sizes at concentration $(0.5,2.5,5$ and $10 \mathrm{ppm})$ were studied under field conditions in disease nursery at Giza and Gemmeza Research Stations, ARC, during summer of 2019-2020 growing seasons. Seed coating treatment, were used. Maize seeds cv. Boushy, susceptible to Harpophora maydis, was used in this 
study. Untreated seeds were used as check treatment. Four replicate plots, 20 maize plants were used in each plot.

Disease assessment

Disease incidence as percentage of infection was recorded 90 day after sowing according to Sabet et al. (1966a).

\section{Statistical analysis}

Data were subjected to statistical analysis ofvariance (ANOVA) test. A complete randomize design was applied and Duncan's multiple rangetests were used for comparing means (Gomez and Gomez, 1984).

\section{RESULTS}

\section{Synthesis and optimization of silica nanoparticles}

In this regard and before silica nanoparticles (SiNPs) synthesis, plant material was subjected to acid treatment by using $1 \mathrm{M}\left(\mathrm{HNO}_{3}\right)$ in a way to purify the reaction mixture from plant impurities. Finally, the preliminary indication for the formation of (SiNPs) can be confirmed by its color change from brown to whitish precipitate as mention before in material and methods. Solutions after titration with $3 \mathrm{M}\left(\mathrm{HNO}_{3}\right)$ were analyzed with the help of UV-Vis spectrophotometer, which displayed a broad peak at $350 \mathrm{~nm}$ (Fig. 1) and (Fig.2A) due to the surface plasmon resonance nature of SiNPs in the reaction solution. The obtained nanoparticles absorb light at different wave lengths and are excited to give a broad peak.

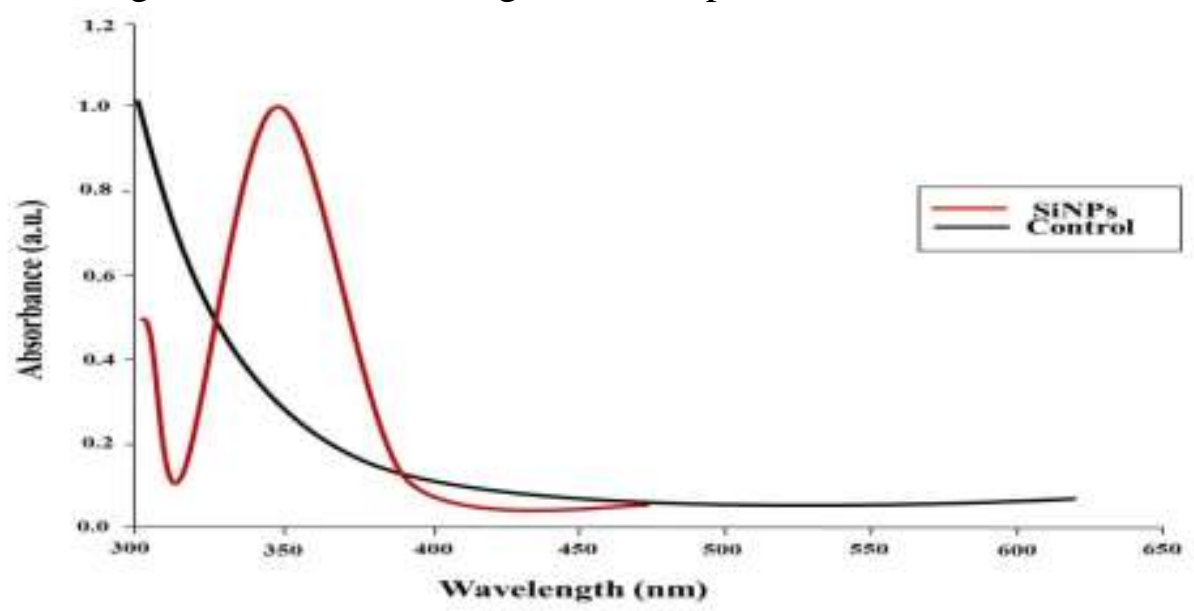

Fig. (1): Plant synthesis of the formed silica nanoparticles: a UV-Vis spectra of the formed SiNPs in comparison with the plant filtrate (negative control).

The Morphology of the biosynthesized SiNPs were examined using HR-TEM (Fig.2B). Measurements indicated the formation of polydispersed spherical shaped SiNPs with $50 \mathrm{~nm} \pm 5.5$ average sizes and - 
$21.5 \mathrm{mV}$ value of zeta potential as indicated by DLS analysis (Fig.2C), which indicated ideal surface charge of the formed SiNPs, which prevent the agglomeration and generate a strong repulsive force among the particles that increase their stability. Also, crystallographic studies of the synthesized SiNPs with XRD instrument displayed a broad and high intensity peak at $22 \circ$ of $2 \theta$ values of $x$-axis corresponding to the amorphous nature of SiNPs which is correlated with JCPDS file No. 010787 of the Joint Committee on Powder Diffraction Standards (Fig.3).

A

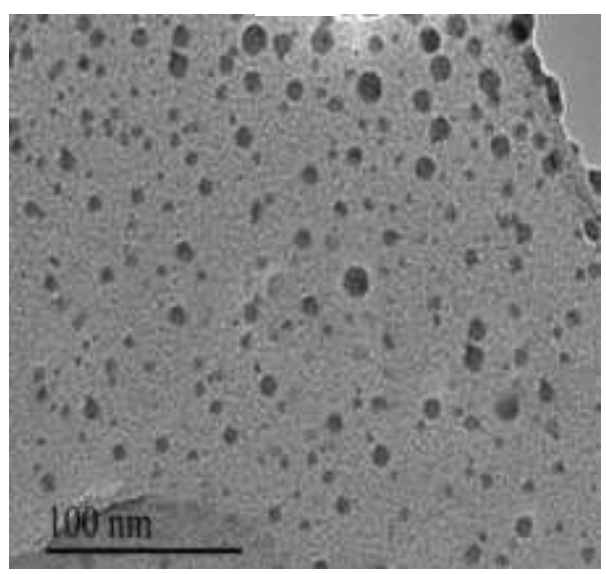

B.

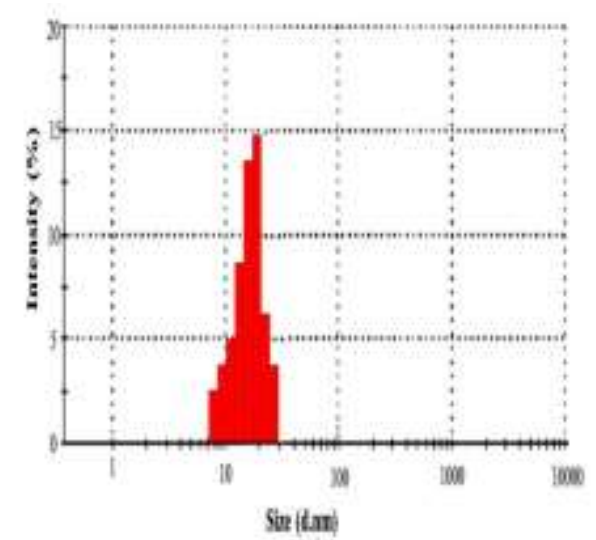

C.

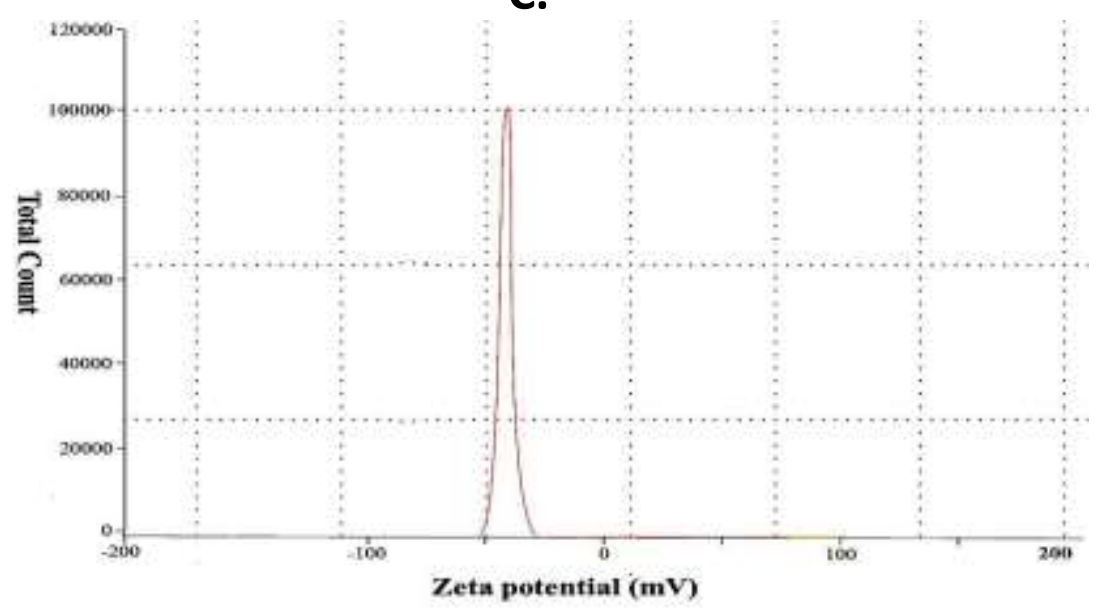

Fig.(2): Characterization of the formed silica nanoparticles:(A.) TEM image of the formed SiNPs, (B) \& (C) the particle and the zeta potential of the formed SiNPs respectively. 


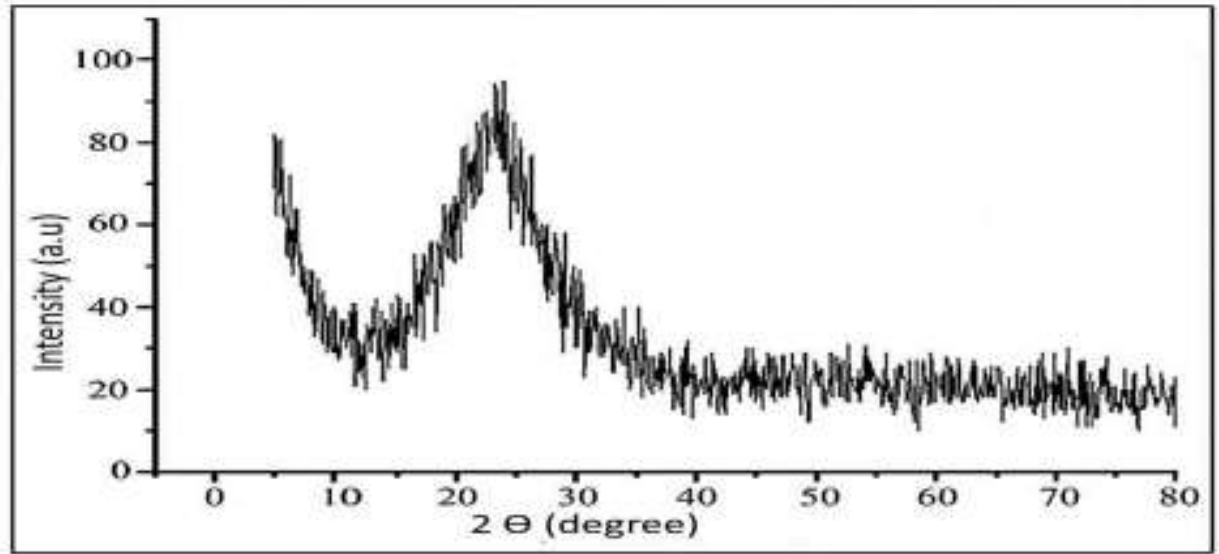

Figure (3): X-ray Diffraction patterns of the formed SiNPs.

The absence of any other XRD peak indicating that the synthesized nanoparticles were pure crystalline in nature. On the other hand, in a way to obtain a smaller SiNPs size, the reaction medium of SiNPs was changed over varied degrees of $\mathrm{pH}(5,7,9,11)$. The color of the reaction mixture and the intensity of the absorbance peaks were $\mathrm{pH}$ dependent. Where, the results showed that SiNPs synthesized at $\mathrm{pH}$ of 5, 7, 9 and 11 presented absorption peaks at $300,350,360$, and $380 \mathrm{~nm}$ respectively.

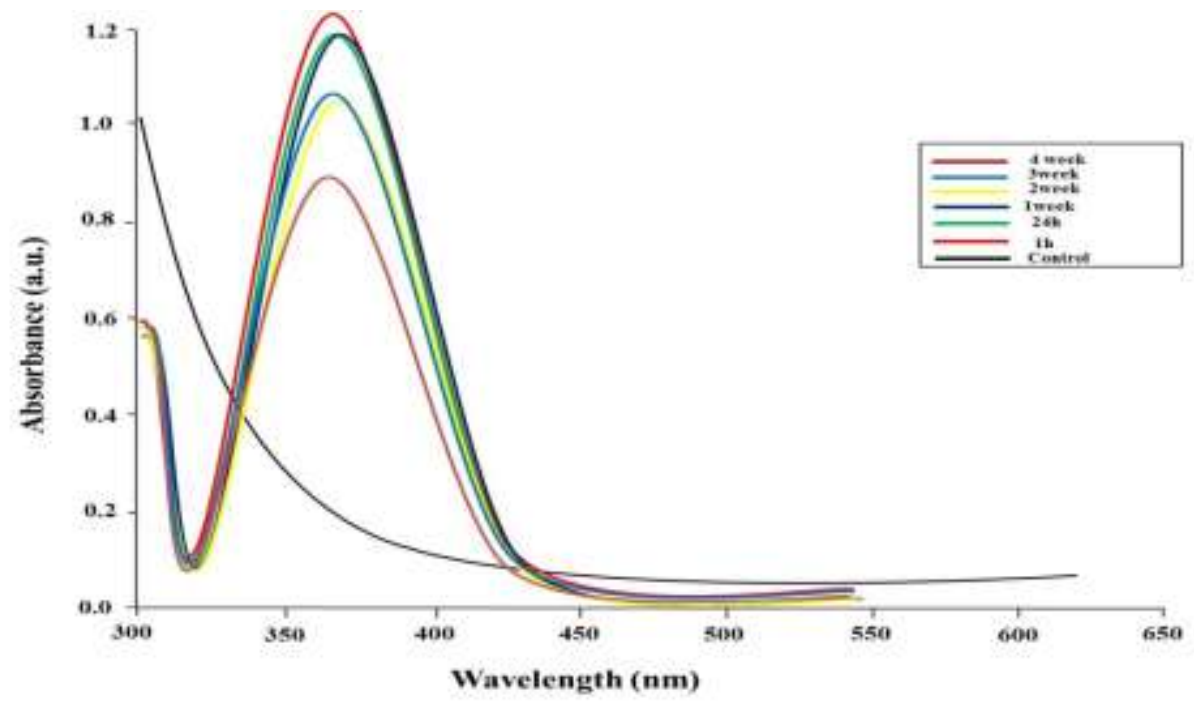

Figure (4): Plant mediated silica nanoparticles: a UV- vis spectra of the formed SiNPs $(20 \mathrm{~nm})$ at different times as indicated during the synthesis and after 4weeks of storage. 
The absorption peaks shifted to shorter wavelength and became narrower at alkaline $\mathrm{pH}$ values, possibly due to the decreased size or anisotropy degree of SiNPs. DLS measurements were carried out to observe the size of the produced SiNPs under $\mathrm{pH}$ values. The results indicated that the smallest SiNPs produced were at $\mathrm{pH}=11$ with $20 \mathrm{~nm}$ in size. Particles obtained at $\mathrm{pH}=9,7$ were larger size, $(40.2,70.5 \mathrm{~nm})$ respectively. At acidic condition $(\mathrm{pH}=5)$, the particle size was $95.5 \mathrm{~nm}$ and cannot observe any characteristic absorbance band for SiNPs formation at better size. Those results indicated that SiNPs were produced in more small size at alkaline medium. Most importantly, the UV spectra results showed that the produced silica nanoparticles $(20 \mathrm{~nm})$ have a high stability over four weeks this was indicated by the absence of red shifting in UV absorbance analysis over a course of time as indicated in Fig. 4.

In vitro effect of nanoparticles on Harpophoramaydis radial growth

The inhibitory effect of SiNPs were evaluated against the linear growth of the highly virulent Harpophora maydis isolate (No. 9) using the culture technique on PDAY medium.

Table 1. Effect of silica nanparticals on Harpophora maydis radial growth

\begin{tabular}{|c|c|c|c|}
\hline \multicolumn{2}{|c|}{ Treatments } & \multirow{2}{*}{$\begin{array}{c}\text { Radial growth }(\mathrm{cm}) \\
8 \text { days }\end{array}$} & \multirow{2}{*}{ Reduction } \\
\hline SiNPs sizes & Concentration ppm & & \\
\hline \multirow{5}{*}{ SiNP- 95.5 nm } & 0.5 & 3.8 & 55.2 \\
\hline & 2.5 & 1.5 & 82.3 \\
\hline & 5 & 1.1 & 87.0 \\
\hline & 10 & 0.5 & 94.1 \\
\hline & mean & 1.73 & 79.5 \\
\hline \multirow{5}{*}{ SiNP-70.2 nm } & 0.5 & 2.5 & 70.5 \\
\hline & 2.5 & 0.6 & 92.9 \\
\hline & 5 & 0.5 & 94.1 \\
\hline & 10 & 0.5 & 94.1 \\
\hline & mean & 1.03 & 88 \\
\hline \multirow{5}{*}{ SiNP-40.2 nm } & 0.5 & 0.7 & 91.7 \\
\hline & 2.5 & 0.7 & 91.7 \\
\hline & 5 & 0.6 & 92.9 \\
\hline & 10 & 0.6 & 92.9 \\
\hline & mean & 0.65 & 92.5 \\
\hline \multirow{5}{*}{ SiNP- $20 \mathrm{~nm}$} & 0.5 & 0.6 & 92.9 \\
\hline & 2.5 & 0.5 & 94.1 \\
\hline & 5 & 0.5 & 94.1 \\
\hline & 10 & 0.5 & 94.1 \\
\hline & mean & 0.53 & 93.8 \\
\hline \multicolumn{2}{|l|}{ Control } & 8.5 & \\
\hline L.S.D. 0.05 & & 1.519 & \\
\hline
\end{tabular}

Results in Table (1) reveal that all tested nanoparticles, SiNP-20, SiNP-40.2, SiNP-70.2 and SiNP-95.5 $\mathrm{nm}$ at the different tested concentration $(0.5,2.5,5$ and $10 \mathrm{ppm})$ significantly inhibited radial growth of Harpophora maydis on PDA compared to control. Generally, growth inhibition (\%) was increased with the increasing of the 
concentrations of all substances. However, the highest effect was recorded beginning from $2.5 \mathrm{ppm}$ concentration being 94.1, 92.9, 91.7 and $82.3 \%$ reduction of SiNP-20 nm, SiNP-70.2 nm, SiNP-40.2 nm and SiNP-95.5 nm, respectively. It was observed that on average, SiNP-20 $\mathrm{nm}(93.8 \%)$ and SiNP-40.2 $\mathrm{nm}(92.5 \%)$ where, the most efficient treatment at any concentration followed by treatment SiNP-70.2 nm (88\%) and SiNP-95.5 $\mathrm{nm}$ achieved $79.5 \%$ reduction.

In vivo effect of SiNPs nanoparticles on maize late wilt:

Pot experiment was carried out to study the effect of seed coated SiNPs treatments at the tested four concentrations $(0.5,2.5,5$ and 10 ppm) against Harpophora maydis the casual organism of maize late wilt. Results in Table (2) show that, all seed treatments with SiNPs significantly reduced the infection \% of late wilt compared with check treatment $(70.8 \%)$ under artificial infestation.

Table. 2 Effect of SiNPs treatments on maize late wilt under greenhouse conditions, Giza, 2019.

\begin{tabular}{|c|c|c|c|c|}
\hline \multicolumn{2}{|c|}{ Treatment } & \multirow{2}{*}{ Ger\% } & \multirow{2}{*}{ Infection (\%) } & \multirow{2}{*}{ Reduction (\%) } \\
\hline SiNPs sizes & Concentration & & & \\
\hline \multirow{4}{*}{ SiNP- $95.5 \mathrm{~nm}$} & 0.5 & 85 & 33.3 & 52.9 \\
\hline & 2.5 & 85 & 27.8 & 60.7 \\
\hline & 5 & 85 & 25.0 & 64.6 \\
\hline & 10 & 81 & 20.1 & 71.6 \\
\hline \multirow{4}{*}{ SiNP- $70.2 \mathrm{~nm}$} & 0.5 & 87.5 & 27.8 & 60.7 \\
\hline & 2.5 & 87.5 & 19.4 & 72.5 \\
\hline & 5 & 85 & 17.0 & 75.9 \\
\hline & 10 & 85 & 14.2 & 79.9 \\
\hline \multirow{4}{*}{ SiNP- $40.2 \mathrm{~nm}$} & 0.5 & 90 & 19.4 & 72.5 \\
\hline & 2.5 & 90 & 16.7 & 76.4 \\
\hline & 5 & 89 & 11.8 & 83.3 \\
\hline & 10 & 86 & 8.7 & 87.7 \\
\hline \multirow{4}{*}{ SiNP- 20 nm } & 0.5 & 90 & 16.7 & 76.4 \\
\hline & 2.5 & 90 & 11.1 & 84.3 \\
\hline & 5 & 90 & 8.7 & 87.7 \\
\hline & 10 & 88 & 8.3 & 88.2 \\
\hline \multicolumn{2}{|l|}{ Control } & 85 & 70.8 & - \\
\hline L.S.D. & & & 10.952 & \\
\hline
\end{tabular}

The most efficient treatments in reducing disease incidence were SiNP-20 and SiNP- $40.2 \mathrm{~nm}$ at 10 and 5ppm concentrations gives $(76.4 \%, 72.5 \%$ reduction at $5 \mathrm{ppm}$, respectively) and at $10 \mathrm{ppm}(88.2$, $87.7 \%$ reduction, respectively) followed by SiNP-70.2 $\mathrm{nm}(79.9 \%)$. The lowest treatment was SiNP-95.5 $\mathrm{nm}$ ranged between 52.9-71.6\% reductions. Germination percentages were not negatively affected and sometimes slightly enhanced.

\section{Field experiments:}

The influence of seed coating with four SiNPson maize late wilt and growth parameters was studied in disease nursery of Harpophora maydis at Giza and Gemmeza Research Stations under field conditions. Untreated plants were used as check. Data presented in Table (3) reveal 
that seed treatment with SiNPs significantly reduced maize infection with late wilt compared with check plants (78.3\% infection at Giza 2019 and $81.7 \%$ at Gemmeza 2020). It was observed that disease incidence was higher in Gemmeza location than Giza. There were significant differences between treatments in yield average of the two seasons. The disease reduction and yield were increase with increasing concentrations. The SiNP-20, $40.2 \mathrm{~nm}$ treatments were the most efficient in decreasing disease incidence and enhancing yield where infection percentage recorded $6.7 \%$ at $10 \mathrm{ppm}$ in first season resulted from both treatments and $6.7 \%$ and $8.3 \%$ in second season in SiNP-20nm and SiNP-40.2nm, respectively. On the other hand, average yield were 29 (ard/fd) in SiNP$20 \mathrm{~nm}$ and $27.3(\mathrm{ard} / \mathrm{fd})$ in case of SiNP-40.2 nm. In contrary, the lowest treatments were those at concentration $0.5 \mathrm{ppm}$ for treatments SiNPs $95.5 \mathrm{~nm}, 70.2 \mathrm{~nm}$ where infection was $34 \%$ and average yield 17.6 (ard/fd) for SiNP-95.5 $\mathrm{nm}$ and it was $26.3 \%$ infection which yielded 18 ( $\mathrm{ard} / \mathrm{fd})$ in SiNP-70.2nm.

Table. 3 Effect of SiNPs on incidence of maize late wilt and yield under field conditions at disease nursery, Giza and Gemmeza, 2019-2020 growing seasons.

\begin{tabular}{|c|c|c|c|c|c|c|}
\hline \multicolumn{2}{|c|}{ Treatment } & \multicolumn{2}{|c|}{ Giza Seasons 2019} & \multicolumn{2}{|c|}{ GemmezaSeasons 2020} & \multirow[b]{2}{*}{$\begin{array}{c}\text { Yield* } \\
(\operatorname{ard} / f d)\end{array}$} \\
\hline SiNPs sizes & Conc. & Infection \% & $\begin{array}{c}\text { Redaction } \\
\%\end{array}$ & Infection \% & $\begin{array}{c}\text { Redaction } \\
\%\end{array}$ & \\
\hline \multirow{4}{*}{ SiNP- $95.5 \mathrm{~nm}$} & 0.5 & 26.7 & 65.9 & 34 & 58.3 & 17.6 \\
\hline & 2.5 & 18.3 & 76.6 & 24 & 70.6 & 20 \\
\hline & 5 & 15.0 & 80.8 & 20 & 75.5 & 20.2 \\
\hline & 10 & 13.3 & 83.0 & 18 & 77.9 & 21.7 \\
\hline \multirow{4}{*}{ SiNP- 70.2 nm } & 0.5 & 23.3 & 70.2 & 26.3 & 67.8 & 18 \\
\hline & 2.5 & 16.7 & 78.6 & 21.7 & 73.4 & 18 \\
\hline & 5 & 15.0 & 80.8 & 18.3 & 77.6 & 23.0 \\
\hline & 10 & 11.7 & 85.0 & 13.3 & 83.7 & 26.0 \\
\hline \multirow{4}{*}{ siNP- $40.2 \mathrm{~nm}$} & 0.5 & 20.0 & 74.4 & 23.3 & 71.4 & 19 \\
\hline & 2.5 & 13.3 & 83.0 & 11.9 & 85.4 & 23 \\
\hline & 5 & 10.0 & 87.2 & 11.7 & 85.6 & 25.6 \\
\hline & 10 & 6.7 & 91.4 & 8.3 & 89.8 & 27.3 \\
\hline \multirow{4}{*}{ SiNP- $20 \mathrm{~nm}$} & 0.5 & 18.3 & 76.6 & 18.2 & 77.7 & 19.7 \\
\hline & 2.5 & 10.0 & 87.2 & 11.7 & 85.6 & 23.7 \\
\hline & 5 & 8.3 & 89.3 & 10.0 & 87.7 & 26 \\
\hline & 10 & 6.7 & 91.4 & 6.7 & 91.7 & 29 \\
\hline \multicolumn{2}{|c|}{ Control } & 78.3 & & 81.7 & & 14 \\
\hline \multicolumn{2}{|l|}{ L.S.D. } & 9.588 & & 7.321 & & 1.571 \\
\hline
\end{tabular}

*: Grain yield per feddan (GYPF), in ardab by adjusting grain yield / plot to grain yield per feddan(adjusted at $\mathbf{1 5 . 5 \%}$ grain moisture).

\section{DISCUSSION}

Late wilt disease of maize caused by Harpophora maydis is one of the most important diseases on maize in Egypt. Breeding of resistant varieties of maize is the most effective method for controlling this disease (El-Shafey et al., 1988). Many attempts were made to control the disease using chemical and biological methods (Abdel-Hamid et al., 
1981; Singh and Siradhana, 1989; El-Mehalowy et al., 2004 and Ashour et al., 2013). In recent years, using pesticide for controlling plant disease resulted in many environmental hazards. Therefore, this work demonstrates the use of safe management method that pose less danger to humans and animals also controlling the disease. In this study, maize seeds coated with silica nanoparticales $(20,40.2,70.2$ and $95.5 \mathrm{~nm})$ were used in vivo and in vitroto control late wilt disease. All tested SiNPs in vitro inhibited the fungal radial growth at different tested concentrations resulted in significant reduction of Harpophora maydis on PDA compared to check treatment. Reduction (\%) increased with increasing of SiNPs concentrations. The reduction in SiNPs sizes 20, $40.2 \mathrm{~nm}$ were higher at any concentration ranged between $94-92 \%$ followed by SiNP$70.2 \mathrm{~nm}$ then SiNP-95.5 $\mathrm{nm}$. The results were in harmony with those obtained by Suriyaprabha et al.(2014) who stated that maize nanosilicatreated plants showed a higher expression of phenolic compounds and a lower expression of stress-responsive enzymes against fungal infection. Maize expressed more resistance to Aspergillus spp., than Fusarium spp. These results showed significant higher resistance in maize treated with silica nanoparticales than with bulk silicon. Hence, silica nanoparticles can be used as an alternative potent antifungal agent against phytopathogens. El-Gazzar and Rabie (2018) reported that using AgNPs against Harpophora maydis alone was efficient more when combined with chemical fungicides MaximXI and Vitavax reduced fungal growth to $51 \%$. The mechanisms responsible for inhibiting of fungal growth by silicon are not well understood. In spite of that, some hypotheses were made by some investigators to illustrate the mode of action of $\mathrm{Si}$ in this respect. Bi et al, (2006) stated that $\mathrm{Si}$ resulted in a collapse and shrinkage of fungal hyphae and spores, which consequently causing the loose of fungal sporulation. Li et al, (2009) observed that ultrastrucural alterations were happened by using transmission electron microscopy, including thickening of the hyphal cell walls. Meanwhile, the inhibitory effect of nanoparticles may be due to release of extracellular enzymes and metabolities (Perez-de-Luque, and Rubiales, 2009) also some studies proposed that nanoparticles may cause structural changes of microbial cell membrane, causing cytoplasm leakage and eventually the cells (Sawai and Yoshikawa, 2004; Brayner et. al.,2006).

Nanoscience and technology are enabling the development of a wide range of materials for plant growth enhancement (Nair et al., 2010). Nano-materials such as titanium and alumina penetrate the plants, thereby improving or decreasing their growth characteristics (Carmen $\boldsymbol{e t}$ al., 2003; Yang and Watts, 2005). Silica ( $\mathrm{SiO} 2)$ is an essential element for monocotyledon plants and it is known to confer biotic and abiotic 
stress tolerance (Rains et al., 2006 and Epstein, 2001). The present study raveled that, in vivo results supported the in vitro ones that all SiNPs treatments, whether in the greenhouse or in field significantly reduced the disease infection when compared to the control. Efficiency in decreasing the disease incidence was increased by increasing the SiNPs concentrations. Also the SiNPs enhanced the germination (\%) than check treatment. Similar results were found by Suriyaprabha et al.(2012) they reported that maize treated with nanosilica showed the highest germination $(98.5 \%)$ while sodium silicate treatment gave $92.5 \%$ germination (bulk silicon). They suggested that immediate uptake of SiNPs through seeds and its role in biochemical induction. Current results also showed that, under greenhouse conditions the SiNPs-20, 40.2 $\mathrm{nm}$ were the most significant treatments in reducing disease incidence followed by SiNPs70.2, 95.5nm. The same trend was obtained in the field. In previous study on bulk silicon, El-Shabrawyet al.(2014) reported that using sodium silicate as an eco-friendly compound, in managing stalk-rot disease complex of maize thatreduced significantly the linear growth of Cephalosporium maydis, Rhizoctonia solani, Fusarium verticillioides and Sclerotium rolfsii in $\mathrm{Si}$ amended-PDA medium. Sodium silicate completely suppressed the tested fungi at concentration $3.0 \%$. Using sodium silicate as seed coating, seed soaking or soil treatment, managed significantly late-wilt infection in greenhouse and stalk-rot disease complex of maize in field trials of sick plots with efficiency reached $76.9 \%$ under field conditions. In contrary in the present investigation, reduction in H.maydis by SiNPs achieved $88.2 \%$ under greenhouse and $91.7 \%$ under field conditions. Moreover, average yield of the two seasons were 29 ( $\mathrm{ard} / \mathrm{fd})$ in SiNP-20nm the highest efficient treatment and while it was $17.6(\mathrm{ard} / \mathrm{fd})$ in case of the lowest ones SiNP-95.5 $\mathrm{nm}$ when compared to control treatment yielded 14 ( $\operatorname{ard} / \mathrm{fd})$. These findings are in agreement with (Yuvakkumar et al.,2011) who reported that SiNPs were important for maize growth enhancement with respect to morphological parameters. However, it was essential to soil microbial biomass and silica during maize cultivation. Their results suggested the use of nanofertilizers in maize crop to enhance yield due to its cost-effectiveness. In addition, the effect of silica sources on the changes in the microbial biomass $(\mathrm{C}$ and $\mathrm{N})$ components in soil as well as the rhizosphere should also be considered. Soil beneficial microorganisms such as nitrogen fixers and phosphatesolubilizing bacteria (PSB) are potent plant growth promoters. On the other hand, silica nanoparticlescould be easily synthesized with a controlled size, shape, and structure, making them highly advantageous delivery vehicles (Mody $\boldsymbol{e t}$ al., 2014). They are commonly produced in a spherical shape with pore-like holes; for example, porous hollow silica 
nanoparticles (PHSNs) or mesoporous silica nanoparticles (MSNs). PHSN and MSN commonly load the pesticide into the inner core to protect the active molecules and, therefore, provide a sustained release. The shell structure of PHSNs protects the active molecules inside the nanoparticles against degradation by UV light. The available literatures suggest that silicon has already been used to enhance plant tolerance against various abiotic and biotic stresses and, therefore, silica nanoparticles seem to be the natural choice for the development of agriproducts against pests (Barik $\boldsymbol{e t}$ al., 2008). Numbers of studies have shown that SiNPs may directly interact with plants and help in improving plant growth and yield (Strout et al., 2013 and Suriyaprabha, 2014). In this regard, silica nanoparticles were observed to form a binary film at the epidermal cell wall after absorption, which may add structural color to plants (Strout et al., 2013). The impact was not limited to coloring; SiNPs were also speculated to act as a strengthening material that may act as an agent to prevent fungal, bacterial, and nematodes infections and thus, may increase disease resistance.

In conclusion, the efficiency of green synthesis SiNPs in reducing late wilt disease incidence in maize was higher. All tested treatments showed similar trends in both vitro and vivo studies. These results suggested the possibility of using SiNPs to control the disease and enhancing maize yield productivity. Moreover, SiNPs may be considered as a green method of controlling plant diseases as an environmentally safe substitute of the synthetic fungicide.

\section{REFERENCES}

Abdel-Hamid, M. S. ; M.F. Abdel-Momeim ; H.A. El- Shafey and S.T. El-Deeb (1981). Biological control of late wilt disease of maize caused by Cephalosporium maydis. Agric. Res. Rev., 59: pp. 253-260.

Adam, F. ; T.S. Chew and J. Andas (2011). A simple template-free sol-gel synthesis of spherical nanosilica from agricultural biomass. J. Sol-Gel Sci Technol, 59: 580-583.

Ali, M.A.Y. (2000). Diversity in isolates of Cephalosporium maydis, the causal of late wilt of maize in egypt. M.Sc. Thesis, Fac. Agric., Cairo Univ., Egypt, 95pp.

Ashour, A.M.A. ; K.K.A. Sabet ; E.M. El-Shabrawy and A.M. lhanshoul (2013). Control of maize late wilt and enhancing plant growth Parameters using rhizobacteria and organic compounds. Egypt. J. Phytopathol., 41 (2):187-207.

Athinaranan, J. ; V.S. Periasamy ; M. Alhazmi ; K.A. Alatiah and A.A. Alshatwi (2015). Synthesis of biogenic silica nanoparticles from rice husks for biomedical applications. Ceramics International, 41(1 A): 275-281. 
Bala, N. ; S. Saha ; M. Chakraborty ; M. Maiti ; S. Das ; R. Basu and P. Nandy (2015). Green synthesis of zinc oxide nanoparticles using Hibiscus subdariffa leaf extract: effect of temperature on synthesis, anti-bacterial activity and anti-diabetic activity. The Royal Soc. of Chemis., 5: 4993-5003.

Bardin, S.D.; H.C. Huang and J.R. Moyer (2004). Control of pythium damping-off of sugar beet by seed treatment with crop straw powders and a biocontrol agent. Biol. Control, 29:453-460.

Barik, T. ; B. Sahu and V. Swain (2008). Nanosilica from medicine to pest control. Parasitol. Res., 103: 253-258.

Bi, Y. ; S.P. Tian ; Y.R. Gue ; Y.H. Ge and G.Z. Qin (2006). Sodium silicate reduces postharvest decay on homi melons: Induced resistance and fungistatic effects. Plant Dis., 90 (4): 279-283.

Bilgrami, K.S. and R.N. Verma (1981). Physiological of Fungi. 2nd ed., pp. 23-27. Vikas Publishing, PTV.,LTd Indian.

Brayner, R. ; R. Ferrari-Iliou ; N. Brivois ; S. Djediat ; M.F. Benedetti and M. Fievet (2006). Toxicological impact studies based on Escherichia coli bacteria in ultrafine $\mathrm{ZnO}$ nanoparticles colloidal medium. Nano Lett., 6:866-870.

Carmen, I.U. ; P. Chithra ; Q. Huang ; P. Takhistov ; S. Liu and J.L. Kokini (2003). Nanotechnology: a new frontier in food science. Food Technol.,57: 24-29.

EL-Gazzar, N.S. and G.H. Rabie (2018). Application of silver Nanoparticles on Cephalosporium maydis in vitro and in vivo. Egypt. J. Microbiol., 53: $69-81$.

El-Mehalowy, A.A. ; N.M. Hassanein ; H.M. Khater ; E.A. Daram El-Din and Y.A. Youssef (2004). Influence of maize root colonization by Rhizosphere actinomycetes and yeast fungi on plant growth and on the biological control of late wilt disease. Int. J. Agric. Biol., 6:599-605.

El-Moghazy, S.M. ; M.E. Shalaby ; Ahlam A. Mehesen and M.H. Elbagory (2017). Fungicidal effect of some promising agents in controlling maize late wilt disease and their potentials in developing yield productivity. Env.Biodiv. Soil Security, 1: 129 - 143.

El-Shafey, H.A.; M.F. Abd-El-Rahim and M.M. Refaat (1979). A new Cephalosporium wilt disease of grain sorghum in Egypt. Proc. 3 rd Egypt, Phytopathology Congress, pp. 513-532.

El-Shafey, H.A. and L.E. Claflin (1999). Late Wilt. In: Compendium of Corn Diseases. (ed. D.G. White), 3rd. St. Paul: APS Press, pp. 43-44.

El-Shafey, H.A.; F.A. El-Shorbagy ; I.I. Khalil and E.M. El-Assiuty (1988). Additional sources of resistance to the late wilt disease 
of maize caused by Cephalosporium maydis. Agric. Res. Rev. Egypt, 66: 221-230.

Elshahawy, E.I. and B.A. El-Sayed (2018). Maximizing the efficacy of Trichoderma to control Cephalosporium maydis, causing maize late wilt disease, using fresh water microalgae extracts. Egyptian J. of Biological Pest Control., 28(48):1-11.

Epstein, E. (2001). Silicon in plants: facts vs. concepts, in Dant off, L.E., Snyder, G.H., Korndoper, G.H. (eds.): Silicon in agriculture. (Elsevier Science, Amsterdam), pp. 1-15.

Games, W. (2000). Phialophora and some similar morphologically littledifferentiated anamorphs of divergent ascomycetes. Stud. Mycol., 45:187-199.

Gomez, K.A. and A.A. Gomez (1984). Statistical Procedure For Agricultural Research. 2 nd (ed.), John Wily \& Sons, New York.

Gopinath, K. ; S. Gowri ; V. Karthika and A. Arumugam (2014). Green synthesis of gold nanoparticles from fruit extract of Terminalia arjuna, for the enhanced seed germination activity of Gloriosa superb. J Nanostruct Chem., 4:115.

Li, Y.C.; Y. Bi ; Y.H. Ge ; X.J. Sun and Y.J. Wang (2009). Antifungal activity of sodium silicate on Fusarium sulphureum and its effect on dry rot of potato tubers. J. Food Sci., 74 (5): 213-218.

Mody, V.V. ; A. Cox ; S. Shah ; A. Singh ; W. Bevins and H. Parihar (2014). Magnetic nanoparticle drug delivery systemsfor targeting tumor. Appl. Nanosci., 4: 385-392.

Nair, R. ; S.H. Varghese ; B.G. Nair ; T. Maekawa ; Y. Yoshida and D.S. Kumar (2010). Nanoparticulate material delivery to plants.Plant Sci., 179: 154-163.

Naseem, T. and M.A. Farrukh (2015). Antibacterial Activity of Green Synthesis of Iron Nanoparticles Using Lawsoniainermis and Gardenia jasminoides Leaves Extract. Journal of Chemistry, Article https://doi.org/10.1155/2015/912342.

Perez-de-Luque, A. and D. Rubiales (2009). Nanotechnology for parasitic plant control. Pest Manage. Sci., 65: 540-545.

Rains, D.W. ; E. Epstein ; R.J. Zasoski and M. Aslam (2006). Active silicon uptake by wheat, Plant Soil, 280:223-228.

Reddy, K.A.G. ; M.J. ; Joy ; T. Mitra ; S. Shabnam and T. Shilp (2012). Nanosilver-A Review. International Journal of Advanced Pharmaceutics, 2(1):9-15.

Sabet, K.A. ; A.S. Samra and N.A. Dawood (1966a). Combined Infection with Stalk-Rot Fungi. In: A. S. Samra and K. A. Sabet, Eds., Investigations on Stalk-Rot Disease of Maize in U.A.R., Ministry of Agriculture, Government Printing Offices, Cairo, pp. 195-204. 
Sabet, K.A. ; A.S. Samra and I.M. Mansour (1966b). Late-wilt of maize and a study of the causal organism. In: Investigations on Stalk-Rot Diseases of Maize in U.A.R. Ministry of Agric., Egypt, Tech. Bull., pp. 8-45.

Sabet, K.A. ; A.M. Zaher ; A.S. Samra and I.M. Mansour (1970). Pathogenicbehaviour of Cephalosporium maydis and $C$. acremonium. Annu. Appl. Biol., 66(2):257-263.

Saleh, A.A. and J.F. Leslie (2004). CephalosporiummaydisIs a Distinct Species in the Gaeumannomyces-Harpophora Species Complex. Mycologia, 96: 1294- 1305.

Saleh, A.A. ; K.A. Zeller ; A.S.M. Ismael ; Zeinab M. Fahmy ; E.M. El- Assiuty and J.F. Leslie (2003). Amplified fragment length polymorphism diversity in Cephalosporium maydisfrom Egypt. Phytopathology, 93:853-859.

Samra, A.S. ; K.A. Sabet and M.K. Hingorani (1963). Late Wilt Disease of Maize Caused by Cephalosporium maydis. Phytopathology, 53: 402-406.

Samra, A.S. ; K.A. Sabet ; M.F. Abdel-Rahim; H.A. El-Shafey ; I.M. Mansour ; F.A. Fadl ; N.A. Dawood and Ikbal H.I. Khalil (1966). Investigations on Stalk-Rot Diseases of Maize in U.A.R. Ministry of Agric., Egypt, Tech. Bull., 204 p.

Sawai, J. and T. Yoshikawa (2004). Quantitative evaluation of antifungal activity of metallic oxide powders $(\mathrm{MgO}, \mathrm{CaO}$ and $\mathrm{ZnO})$ by an indirect conductimetric assay. J. Applied Microbiol., 96: 803-809.

Shende, S. ; A.P. Ingle ; A. Gade and M. Rai (2015). Green synthesis of copper nanoparticles by Citrus medica Linn. (Idilimbu) juice and its antimicrobial activity. World J Microbiol Biotechnol, 31:865-873.

Singh, S.D. and B.S. Siradhana (1989). Chemical control of late wilt of maize induced by Cephalosporium maydis. Indian Journal of Mycology and Plant Pathology, 19:121-122.

Strout, G. ; D.S. Russell ; P.D. Pulsifer ; S. Erten ; A. Lakhtakia and W.D. Lee (2013). Silica nanoparticles aid in structural leaf coloration in the Malaysian tropical rainforest under storey herb Mapania caudate. Ann. of Botny.112(6): 1141-1148.

Suriyaprabha, R. ; G. Karunakaran ; R. Yuvakkumar ; P. Prabu ; V. Rajendran and N. Kannan (2014). Effect of silica nanoparticles on microbial biomass and silica availability in maize rhizosphere. Biotechnology and Applied Biochemistry, 61(6):668-75.

Suriyaprabha, R. ; G. Karunakaran ; R. Yuvakkumar ; V. Rajendran ; P. Prabu and N. Kannan (2012). Growth and 
physiological responses of maize (Zea mays. L) treated with silica nanoparticles in soil. J. Nanopart. Res., 14:1-14.

Yang, L. and D.J. Watts (2005). Particle surface characteristics may play an important role in phytotoxicity of alumina nanoparticles. Toxicol. Lett., 158: 122-132.

Yugandhar, P. and N. Savithramma (2015a). Leaf Assisted Green Synthesis of Silver Nanoparticles from Syzygium alternifolium (Wt.) Walp. Characterization and antimicrobial studies an endemic, endangered medicinal tree taxon. Journal Nano Biomedicine and Engineering, 7(2):29-37.

Yugandhar, P. and N. Savithramma (2015b). Biosynthesis, characterization and antimicrobial studies of green synthesized silver nanoparticles from fruit extract of Syzygium alternifolium (Wt.). Walp. an endemic, endangered medicinal tree taxon. Appl. Nanosci. http://www.springer.com/materials/nanotechnology/journal/13204

Yugandhar, P. and N. Savithramma (2016). Biological synthesis of silver nanoparticles from Adansonia digitata $\mathrm{L}$. fruit pulp extract, characterization, and its antimicrobial properties. $J$ intercult Ethnopharmacol, 5(1): 79-85

Yugandhar, P. and N. Savithramma (2013). Green synthesis of calcium carbonate nanoparticles and their effects on seed germination and seedling growth of Vignamungo (L.). Hepper., 1(8):89-103.

Yugandhar, P. ; R. Haribabu and N. Savithramma (2015). Synthesis, characterization and antimicrobial properties of greensynthesised silver nanoparticles from stem bark extract of Syzygium alternifolium (Wt.) Walp. 3 Biotech, 5(6): 1031-1039.

Yuvakkumar, R. ; V. Elango ; V. Rajendran ; N. Kannan and P. Prabu (2011). Influence of Nanosilica Powder on the Growth of Maize Crop (Zea mays L.). Int. J. Green Nanotechnol., 3: 180-190.

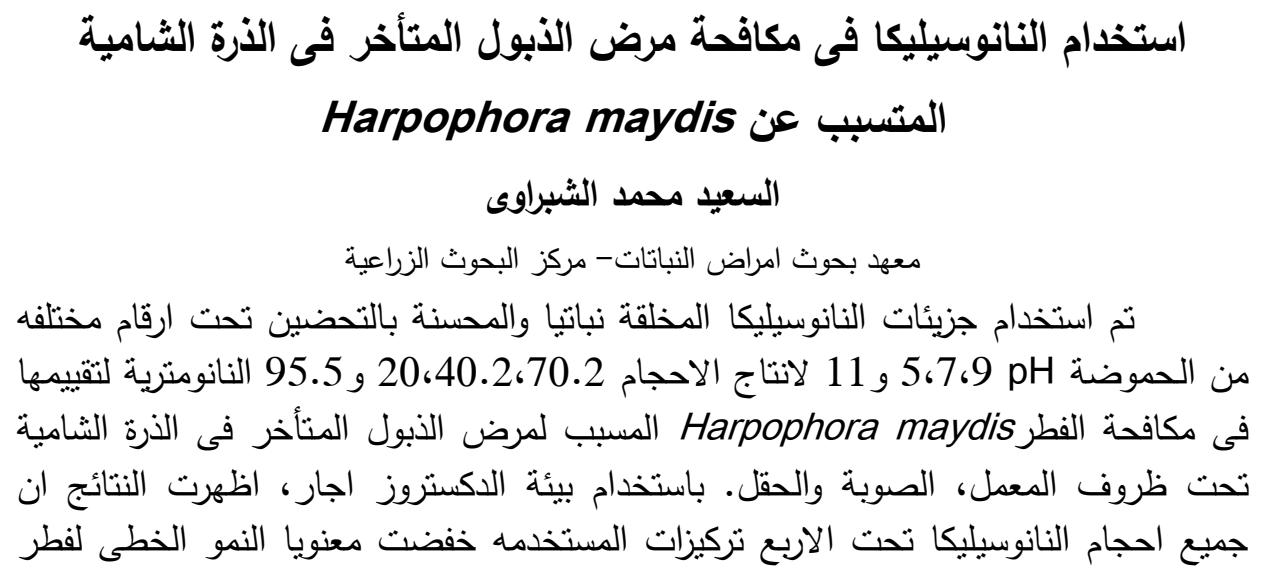


20-2. maydis

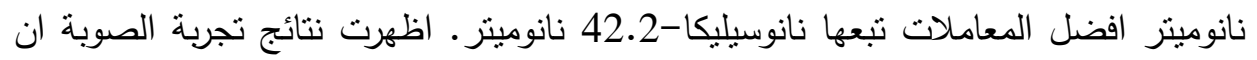

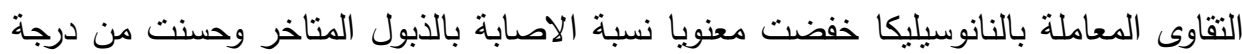
الانبات بالمقارنة بنسبة الاصابة فى الكنترول 70.8\%

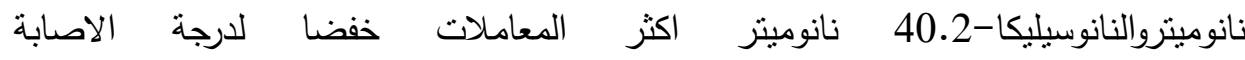

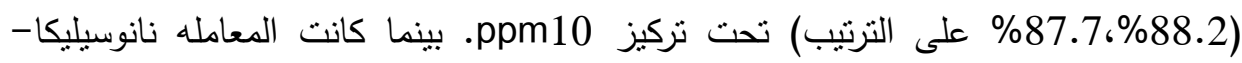

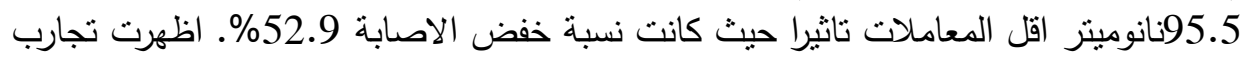

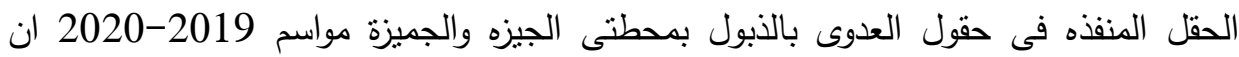

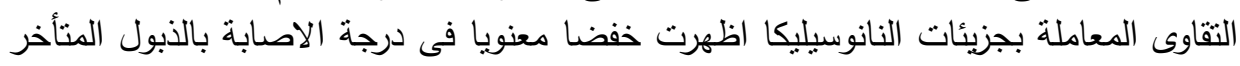

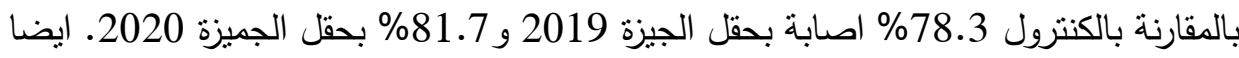

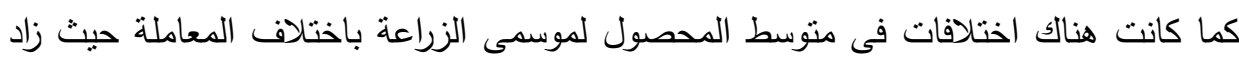

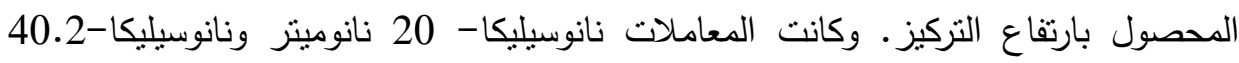

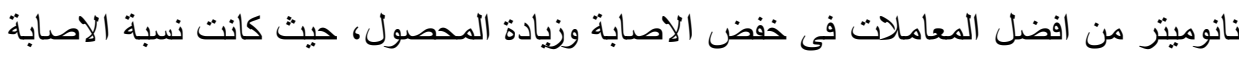

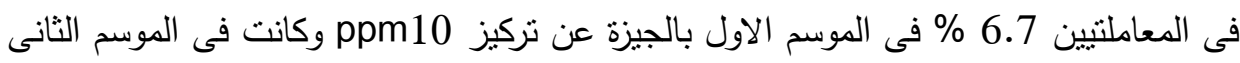

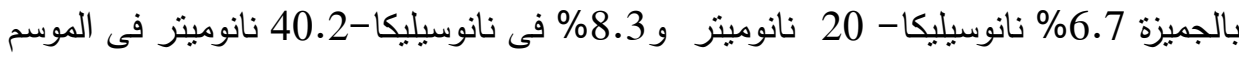

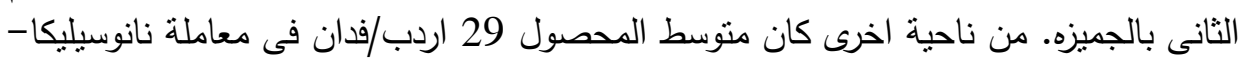

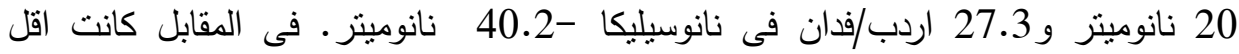

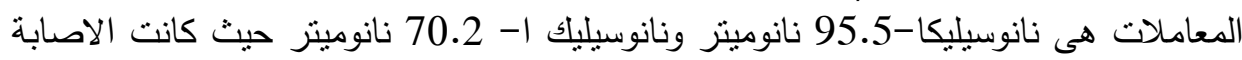
34 ومحصول 17.6 اردب/فدان بالمعاملة حجم

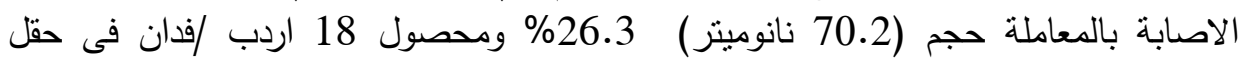

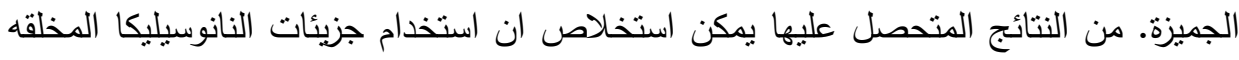

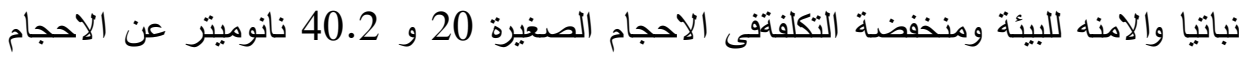
الكبيرة، كانت فعالة فى مكافحة مرض الذبئة ومنيول النتأخر ورفع انتاجية محصول الذرة. 